\title{
LXR agonist improves peripheral neuropathy and modifies PNS immune cells in aged mice
}

\author{
Chaitanya K. Gavini ${ }^{1}$, Nadia Elshareif ${ }^{1}$, Gregory Aubert ${ }^{1,3}$, Anand V. Germanwala ${ }^{2}$, Nigel A. Calcutt ${ }^{4}$ and
} Virginie Mansuy-Aubert ${ }^{1 *}$ (D)

\begin{abstract}
Background: Peripheral neuropathy is a common and progressive disorder in the elderly that interferes with daily activities. It is of importance to find efficient treatments to treat or delay this age-related neurodegeneration. Silencing macrophages by reducing foamy macrophages showed significant improvement of age-related degenerative changes in peripheral nerves of aged mice. We previously demonstrated that activation of the cholesterol sensor Liver X receptor (LXR) with the potent agonist, GW3965, alleviates pain in a diet-induced obesity model. We sought to test whether LXR activation may improve neuropathy in aged mice.

Methods: 21-month-old mice were treated with GW3965 (25 mg/Kg body weight) for 3 months while testing for mechanical allodynia and thermal hyperalgesia. At termination, flow cytometry was used to profile dorsal root ganglia and sciatic nerve cells. Immune cells were sorted and analyzed for cholesterol and gene expression. Nerve fibers of the skin from the paws were analyzed. Some human sural nerves were also evaluated. Comparisons were made using either $t$ test or one-way ANOVA.
\end{abstract}

Results: Treatment with GW3965 prevented the development of mechanical hypersensitivity and thermal hyperalgesia over time in aged mice. We also observed change in polarization and cholesterol content of sciatic nerve macrophages accompanied by a significant increase in nerve fibers of the skin.

Conclusions: These results suggest that activation of the LXR may delay the PNS aging by modifying nerve-immune cell lipid content. Our study provides new potential targets to treat or delay neuropathy during aging.

Keywords: Liver X receptors, GW3965, Peripheral neuropathy, Aging

\section{Background}

Aging-related peripheral neuropathy and neuropathic pain contributes significantly to decreased quality of life in the elderly. Surveys report a prevalence of neuropathy and neuropathic pain of between 20 and $58 \%$ in people aged 60 and above, with prevalence directly proportional to age [1-4]. With age, the peripheral nervous system (PNS) undergoes pathophysiological changes that are also observed in people suffering with neuropathy, such

\footnotetext{
*Correspondence: vmansuyaubert@luc.edu

${ }^{1}$ Cell and Molecular Physiology, Stritch School of Medicine, Loyola University Chicago, Maywood, IL 60153, USA

Full list of author information is available at the end of the article
}

as atrophy of large, myelinated fibers and thinning of the myelin sheath [5-7]. Some patients aged or otherwise develop peripheral neuropathies without a clear diagnosis, and the sural nerve biopsy can provide a diagnosis for the neuropathy $[8,9]$. Studies from others and ours propose that neuropathy is significantly associated with lipid homeostasis in the PNS $[6,8,10-12]$. Understanding lipid metabolism in cells of the PNS is critical for understanding the pathophysiology of and developing novel targeted treatments for neuropathy.

Many forms of disease-initiated peripheral neuropathy share a common pathogenic mechanism that involves modifications to neuro-immune interactions mediated by inflammatory signals [13]. Immune cells original author(s) and the source, provide a link to the Creative Commons licence, and indicate if changes were made. The images or other third party material in this article are included in the article's Creative Commons licence, unless indicated otherwise in a credit line to the material. If material is not included in the article's Creative Commons licence and your intended use is not permitted by statutory regulation or exceeds the permitted use, you will need to obtain permission directly from the copyright holder. To view a copy of this licence, visit http://creativecommons.org/licenses/by/4.0/. The Creative Commons Public Domain Dedication waiver (http://creativeco mmons.org/publicdomain/zero/1.0/) applies to the data made available in this article, unless otherwise stated in a credit line to the data. 
expressing CD45 and CD11B enter the PNS from circulation and help to maintain the integrity of the nerve, in diseases models, they were shown to play a role in both regeneration and degeneration [14]. Damage to the nerve changes resident immune system that may be quantitative-loss of CD45+leukocytes or increased infiltration of CD45+leukocytes during inflammation-, or qualitative-change of macrophage phenotype [15]. Reduced recruitment of macrophages to the PNS, or their impaired capacity to phagocytosis results in impaired regeneration and maintenance of nerve integrity [16]. MHC class II (IA/IE) expressing inflammatory macrophages (as referred as M1), are less capable of phagocytosis than M2 macrophages (expressing CD206). Neuronal inflammation is implicated in the pathogenesis of several neurodegenerative diseases [17]. Recent studies have demonstrated that an increase in the number of macrophages in the dorsal root ganglia (DRG) and the sciatic nerve (SN) alters pain perception [18-20]. Macrophages and neutrophils are pivotal in clearance of debris during Wallerian degeneration following physical nerve injury [21, 22]; macrophages also form a bridge to facilitate migration endothelial cells and Schwann cells during nerve regrowth [23, 24]. Dysregulation of macrophage function can be detrimental to peripheral nerve. For example in Guillain-Barre syndrome, macrophages penetrate myelinating fibers at the nodes of Ranvier and promote axonal damage [25], while endoneurial macrophages are activated by Schwann cells and damage nerve fibers in a model of charcot-marie-tooth [26]. Targeting macrophages as an approach to treating age-related neuropathy is suggested by a report that macrophage silencing, achieved by blocking a cytokine receptor, reduced endoneurial foamy macrophages and significantly improved age-related degenerative changes in peripheral nerves of 24-month-old mice [6].

Circulating cholesterol and cholesterol pathways are linked to development and progression of neuropathy and studies have identified lipid-filled macrophages in the nerves of 24-month-old mice [12, 27, 28], which may reflect clearance of membrane debris. The clearance of such macrophages has been extensively studied in atherosclerosis, where dysfunction of lipid efflux from macrophages leads to inflammatory pathology [29]. Liver X receptors (LXR) are ligand-activated nuclear receptors that bind metabolites of cholesterol [30,31], regulate cellular lipid efflux $[32,33]$ and have been involved in type II diabetic neuropathy [34]. In atherosclerosis, oxysterols derived from phagocytosis of apoptotic or necrotic cells activate the LXR pathway in naive macrophages, upregulating genes involved in cholesterol efflux, such as ATP binding cassette A1 (ABCA1) [35]. Overexpression of $A B C A 1$ induces expression of the anti-inflammatory cytokines and other markers of M2 macrophages [36-38]. The role of LXR in immune cells located in the peripheral nerve system had not been investigated. In this study, we, therefore, treated aged mice with the selective LXR agonist GW3965 and evaluated some immune cell changes within the DRG and SN. We observed nerve regeneration and amelioration of neuropathic pain in aged mice treated with GW3965. Further experiments suggest that LXR activation changes nerve macrophage cholesterol efflux modifying the macrophage phenotypes.

\section{Methods \\ Mice}

All studies were conducted in accordance with recommendations in the Guide for the Care and Use of Laboratory Animals of the National Institutes of Health and the approval of the Loyola University Chicago Institutional Animal Care and Use Committee. C57BL/6 J mice (\#000664, IMSR_JAX:000664) were obtained from Jackson laboratory (Maine, USA). All mice were housed under a 12:12 h light/dark cycle with free access to food (Teklad LM-485: Envigo, Indiana, USA) and water. All studies were performed using male mice with the experimenter blinded to treatment and recorded as per the ARRIVE guidelines [39].

\section{Human subjects}

Informed consent was obtained from all human subjects (37yrs and 84yrs old, both females, patients undergoing leg amputations for trauma) prior to sural nerve sample collection in strict accordance with the rules and guidelines stipulated by the Loyola University Chicago Internal Review Board (IRB). All experimental protocols were approved by the Loyola University Chicago IRB (protocol \# 210567020519). If a subject does not wish to participate, s/he is excluded from the study. During the surgery, the neurosurgeon resected the sural nerve (roughly $15 \mathrm{~mm}$ in length) for the study and the whole samples were processed for immune cells in the sciatic nerve as detailed below.

\section{In vivo agonist treatment}

21-month-old mice $(\mathrm{n}=10-12)$ were treated with vehicle or LXR agonist (GW3965; $25 \mathrm{mg} / \mathrm{kg}$ body weight) (Axon Medchem, Virginia, USA) by intraperitoneal injection twice weekly for 12 weeks (each i.p separated by 3 days), starting at 21 months of age. Tissues were rapidly dissected and processed or frozen in liquid nitrogen before analysis.

\section{Mechanical sensitivity}

6 month $(n=6), 12$ month $(n=6)$, vehicle or GW3965 treated 21-24 month-old mice ( $n=10-12 /$ group) were 
evaluated in a quiet room, at a constant temperature of $24{ }^{\circ} \mathrm{C}$ and acclimated to the von Frey chambers for at least $40 \mathrm{~min}$, but not restrained in the chamber any longer than necessary to minimize stress and discomfortinduced behavioral variations. Mice were investigated for mechanical allodynia using phasic stimulation of the hind paws with von Frey filaments as described before [10]. Briefly, after acclimation to the testing chambers, mice were then subjected to iterative stimulation with calibrated von Frey filaments $(0.16 ; 0.4 ; 1 ; 2 ; 4 ; 6 ; 8$ g: North Coast Medical, California, USA). Filaments were applied 6 times for 1 at $1 \mathrm{~s}$ intervals with a 5 min break between each series of stimulations to the plantar surface of the mice hind limbs. A response to stimulation was defined as paw withdrawal or licking of the stimulated paw [40]. Response frequency for each filament was recorded and $50 \%$ threshold calculated. The test was performed once every 3 weeks for the vehicle or GW3965 treated agematched mice for 12 weeks starting at 21 months to 24 months. A single trained investigator made all baseline and experimental measurements for these series of experiments while remaining blinded to the treatment groups.

\section{Thermal nociception}

6 month $(n=6), 12$ month $(n=6)$, vehicle or GW3965 treated 21-24 month-old mice ( $n=6$ /group) were investigated for heat nociception using Plantar Test Apparatus (Hargreaves Method: IITC Life Science, California, USA) (SCR_012152) [40]. Briefly, after acclimation to testing chambers, tests were performed on the hind paw plantar surface using a focused, radiant heat light source with a built-in timer displaying reaction time in seconds. The heating rate was $1^{\circ} \mathrm{C} / \mathrm{s}$ and a cutoff time of $20 \mathrm{~s}$ was set to avoid tissue damage. The test was performed once every 3 weeks for the vehicle or GW3965 treated age-matched mice for 12 weeks starting at 21-24 months.

\section{Nerve fiber densities}

Analysis of fiber density was performed routinely as described in detail elsewhere [40]. Briefly, footpads were collected from hind paws ( $n=4-5 /$ group) and transferred to Zamboni's fixative for $4 \mathrm{~h}$ on ice before washing with PBS and embedding in paraffin block. $6 \mu \mathrm{m}$ sections were cut using a rotary microtome (Leica, Illinois, USA) and mounted onto glass slides. Samples were immunostained with anti-PGP9.5 antibody (1:1000, \#78630504, AB_2210505; AbD Serotec, California, USA) and nerve fiber density was quantified under blinded conditions by light microscopy at $40 \times$ magnification. All nerve fragments in the epidermis and papillary dermis were counted for detection of nerve fiber terminal loss. The length of the paw skin was traced under light microscope and nerve density was reported as profiles $/ \mathrm{mm}$.

\section{Cell dissociation}

Following euthanasia by isoflurane and cervical dislocation ( $n=6-9 /$ group), DRG and the maximal length of the $\mathrm{SN}$ (region identical between each mice and using the step-by-step approaches published elsewhere [41]) were dissected and placed in trypsin/collagenase A $(1.25 \mathrm{mg} /$ ml each) (\#T1426, \#C9407, respectively, Sigma-Aldrich, Missouri, USA) in PBS and incubated for $30 \mathrm{~min}$ at $37^{\circ} \mathrm{C}$ in a $5 \% \mathrm{CO}_{2}$ incubator. Digested tissues were dissociated into single cell suspension using fire polished glass pipettes before centrifuging at $300 \mathrm{~g}$ for $5 \mathrm{~min}$. The resuspended cells were processed as described below.

\section{Flow cytometry}

Cells dissociated from the DRG and whole SN were stained with fluorescently conjugated antibodies (CD45, CD11B, I-A/I-E, F4/80, CD206) (\#157604, AB_2876536; \#101212, AB_312795; \#107650, AB_2566438; \#123114, AB_893478; \#141734, AB_2629637, respectively; BioLegend, California, USA) as previously described [42-44]. Briefly, dissociated single cells from DRG and SN were incubated in blocking solution (5\% horse serum in PBS) for $30 \mathrm{~min}$ on ice. After pelleting the cells at $300 \mathrm{~g}$ for $5 \mathrm{~min}$, above-mentioned fluorescently labelled antibodies were assayed at 1:1000 dilution and incubated for $1 \mathrm{~h}$ on ice. Cells were then washed and resuspended in blocking buffer before analyzing. Cells that were positive for both CD45 and CD11B were sorted from other dissociated cells for further analysis. Flow cytometry data were acquired using a BD FACS Aria III (BD Biosciences, California, USA) and data analyzed using FlowJo (BD Biosciences, California, USA).

\section{Quantitative PCR}

mRNA was extracted from sorted CD45 + /CD11B + cells ( $n=6-8$ /group) using Arcturus PicoPure RNA Isolation Kit (ThermoFisher, Massachusetts, USA) before generating cDNA using High Capacity cDNA Reverse Transcription Kit (ThermoFisher, Massachusetts, USA). For all genes of interest, qPCR was performed using Sybr green-based assay (Roche, Indiana, USA) using IDT primers (IDT technologies, Iowa, USA). $18 \mathrm{~s}$ was used to normalize data and quantification was done using $\Delta \Delta C T$ method with the mean value of the vehicle treated group set at $100 \%$.

\section{Cholesterol assay}

Cholesterol content in sorted CD45+/CD11B + cells ( $n=6-8$ /group) or in serum of mice $(n=6 /$ group $)$ was assessed using the Amplex Red Cholesterol Kit 
(ThermoFisher, Massachusetts, USA) following manufacturer's instructions. Data are normalized to protein content with the mean value of the vehicle treated group set at $100 \%$.

\section{BMDM isolation}

Bone derived macrophages were obtained from C57BL/6 J mice (IMSR_JAX:000664) (21 month-old mice) $(n=3)$ as previously described [45]. Briefly, femurs and tibia were obtained from mice after euthanasia using isoflurane and cervical dislocation and marrow flushed using RPMI-1640 supplemented with 10\% FBS, antibiotics, and glutamine. The fluid containing dissociated marrow cells was passed through a cell strainer. Cells were plated onto coverslips coated with poly-l-lysine in a 12-well plate and allowed to attach overnight in a humidified incubator with $5 \% \mathrm{CO}_{2}$ at $37^{\circ} \mathrm{C}$. The following day, coverslips were washed 3 times with warm phosphate buffered saline (PBS) to remove non-adherent cells before the media was replaced with RPMI-1640 supplemented with $10 \%$ FBS, antibiotics, glutamine, and 10\% L929 conditioned media to differentiate the cells. Once fully differentiated ( day 6 ), cells were processed for further experiments.

\section{Immunofluorescence}

Fully differentiated macrophages were treated with either vehicle or $1 \mu \mathrm{M}$ GW3965 for $24 \mathrm{~h}$, then co-incubated with $10 \mu \mathrm{g} / \mathrm{mL}$ DiI-oxLDL (ThermoFisher, Massachusetts, USA) for another $24 \mathrm{~h}$ ( $n=3$ experiments in triplicate). Cells were then washed with ice cold PBS and fixed with 4\% PFA for 15 min. After washing with PBS, coverslips were co-stained with DAPI and mounted for imaging. Images were captured using Olympus IX80 Inverted Microscope (Olympus Corporation, Massachusetts, USA) equipped with an X-Cite $120 \mathrm{Q}$ fluorescent light source (Lumen Dynamics, Ontario, Canada) and a CoolSNAP HQ2 CD camera (Photometrics, Arizona, USA). Image processing and quantification $(n=50$ cells/group) was performed using CellSens (Olympus
Corporation, Waltham, Massachusetts) and Fiji software (SCR_002285).

\section{Oxygen consumption assay}

A Seahorse XFe96 Analyzer (Agilent, California, USA) was used to measure oxygen consumption rate (OCR) [46-48] of macrophages (seeding density 100,000 cells/ well) treated with oxLDL and GW3965 as described above. Briefly, $1 \mathrm{~h}$ before the assay, culture media was aspirated from the cells in the plate and Seahorse XF assay media supplemented with $20 \mathrm{mM}$ glucose and $2 \mathrm{mM}$ glutamine was applied and equilibrated in a $\mathrm{CO}_{2}$ free incubator. Oligomycin $(2 \mu \mathrm{M}$, final) (inhibits complex $\mathrm{V}$ of the electron transport chain (ETC)), carbonyl cyanide-4-(trifluoromethoxy)phenylhydrazone (FCCP, uncoupling agent) $(2 \mu \mathrm{M}$, final), antimycin A and rotenone $(0.75 \mu \mathrm{M}$, final) (inhibit complexes I and III, inhibiting ETC activity) were sequentially injected into the system to induce changes in ETC activity. OCR values were normalized to total protein in individual wells ( $n=15$ wells/group).

\section{Quantification and statistical analysis}

All data are represented as Mean \pm S.E.M. Analysis and graphing were performed using GraphPad Prism 9.1.2 (SCR_002798; California, USA). For single group comparisons, either a 1- or 2-tailed $t$ test was used as appropriate. Multiple comparisons were performed using one-way ANOVA. The number of experiments/replicates and mice for each experiment are described in figure legends.

\section{Results}

Aged mice developed features of neuropathic pain and small fiber neuropathy.

We used the von Frey and Hargreaves tests to longitudinally evaluate sensitivity of 6-month, 12-month, and 21-month-old mice (Fig. 1). During the von Frey test, we observed a significant decrease in the $50 \%$ response threshold of mice starting at 12 months of age and

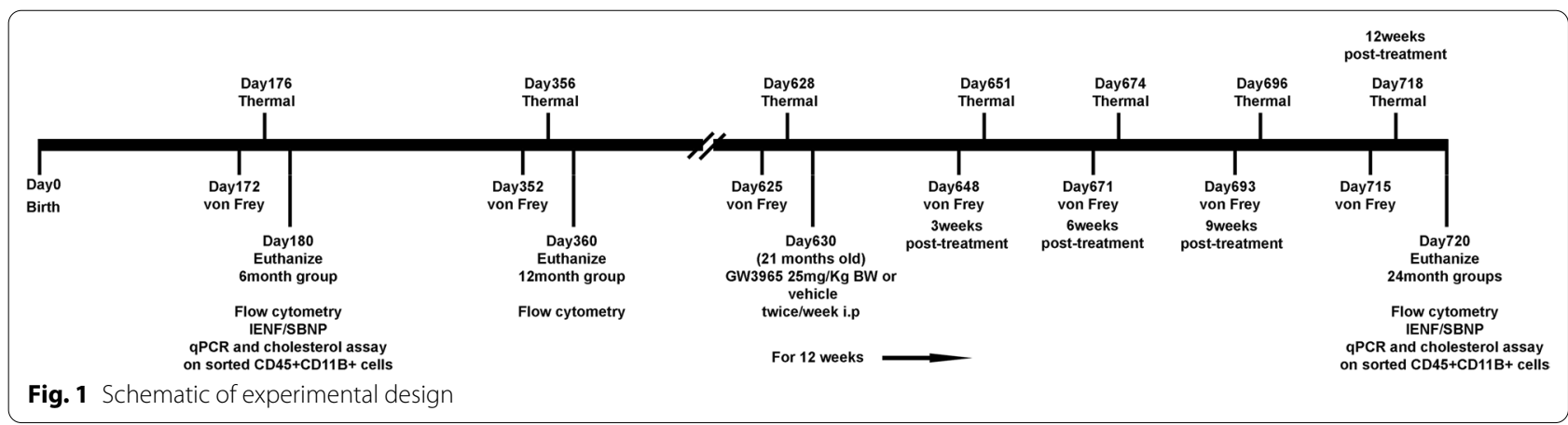


progressing at 21 months of age (Fig. $2 \mathrm{~A})(n=6 /$ group), suggesting an increased sensitivity to innocuous stimuli with age. Mice also developed sensitivity to heat, with significant hyperalgesia detected in 21-month-old mice compared to 12-month-old mice (Fig. 2B) ( $n=6 /$ group). Thus, age significantly affects escape responses to both mechanical and thermal stimuli.

We then quantified sensory nerve density in the epidermis (intraepidermal nerve fibers; IENF and sub-basal nerve plexus; SBNP). We observed a significant decrease in both IENF (Fig. 2C, E) ( $n=4-6 /$ group) and SBNP (Fig. 2D, E) ( $n=4-6 /$ group) density in 24 month-old mice compared to 6-month-old mice demonstrating that aging led to distal sensory neuropathy.

\section{Age-related accumulation of macrophages in the dorsal root ganglia and sciatic nerve}

Previous studies in mice have identified macrophages as contributors to assorted peripheral neuropathies [49]. We performed flow cytometry of cells derived from the DRG and SN and used specific cell surface markers to identify macrophage numbers and phenotypes (Fig. 3A). We observed a significant temporal increase in the percentage of cells expressing the pan-macrophage markers $\mathrm{CD} 45+\mathrm{F} 4 / 80+$ in both the DRG and SN, with the highest increase occurring between 12 and 24 months of age (Fig. 3B, C) ( $n=6 /$ group). We also observed a temporal increase in percentage of cells identified as pro-inflammatory macrophages (CD45+IAIE +) in the DRG and $\mathrm{SN}$ (Fig. 3B, C) ( $n=6 /$ group) and a significant increase in the percentage of potentially anti-inflammatory macrophage $\mathrm{M} 2(\mathrm{CD} 45+\mathrm{CD} 206+)(n=6$ /group $)$ population in both DRG and SN of 12-month-old mice compared to 6-month-old mice (Fig. 3B, C) ( $n=6 /$ group). In contrast, the proportion of M2 macrophages significantly decreased in the DRG and SN of 24-month-old mice (Fig. 3B, C) ( $n=6$ /group).

Comparison of sural nerve biopsies from two individuals (subject 1: 84 years and subject 2: 37 years) demonstrated a considerably lower percentage of M2 macrophages in older individual compared to the younger individual (Additional file 1: Fig. S1A). Similar to mice, we also observed a higher percentage of M1 macrophages in older individual compared to younger individual (Additional file 1: Fig. S1A). These data that will need to be confirmed with larger sample size suggest that phenotype of activated macrophages may change with age.

\section{LXRs agonist delays progression of age-associated neuropathic pain and neuropathy}

We next assessed whether activation of LXRs using its potent and selective agonist GW3965 could change the progression of age-related neuropathic pain and neuropathy. Aged (21 month-old) mice were injected with the LXRs agonist GW3965 (25 mg/kg body weight) or vehicle for 12 weeks [10]. LXRs activation may have systemic effects and as we published before routes and modes of administration would lead to more or less adverse effects. As we and others showed before [10, 34], our treatment paradigm does not lead to hypercholesterolemia and hypertriglyceridemia (Additional file 1: Fig. S1D, E). Compared to vehicle, treatment with GW3965 prevented the further development of mechanical hypersensitivity and heat hyperalgesia over time, with a significant difference observed after 6 weeks of treatment for mechanical sensation ( $n=10-12 /$ group) and after 9 weeks of treatment for heat sensation (Fig. 4A, B) ( $n=6 /$ group). We then evaluated the effect of GW3965 on IENF and SBNP density in the paw of these mice. Compared to vehicle treated mice, we observed a trend to increased IENF of 24-month-old mice treated with GW3965 (Fig. 4C, E) ( $n=3-4$ /group) and a significant increase in SBNP density in 24-month-old mice treated with GW3965 (Fig. 4D, E) ( $n=3-4$ /group). These data suggest that LXRs activation either attenuated distal degeneration or stimulated nerve regeneration and demonstrate that in vivo activation of LXRs using GW3965 can improve indices of agerelated neuropathic pain and sensory neuropathy.

\section{Effect of LXRs agonist treatment on macrophage in the DRG and SN}

To assess whether LXR activation modifies PNS immune cells we quantified some immune cells in the DRG and $\mathrm{SN}$ using flow cytometry. Although there was not a significant change in proportions of any macrophage phenotype in the DRG (Fig. 5A) ( $n=8 /$ group), we did observe a significant increase in percentage of both pro-inflammatory $(\mathrm{CD} 45+\mathrm{IAIE}+)$ M1 macrophages and anti-inflammatory (CD45+CD206+) M2 macrophages in the SN of mice treated with GW3965 (Fig. 5B) ( $n=8 /$ group).

Transcript levels of multiple lipid efflux mediators showed an age-related decrease (Additional file 1: Fig. S1B) ( $n=8$ /group). LXRs play an important role in regulating macrophage cholesterol efflux in other tissues [32, 33] but their role in regulation of cholesterol in macrophages of peripheral nerves had not to our knowledge been evaluated. We sorted CD45 + CD11B + cells from the DRG and SN and studied Abca1, Srebpf (Sterol regulatory element-binding transcription factor 1 ) and Cd36 (cluster of differentiation 36, scavenger receptor) transcript levels, these genes are involved in lipid de novo production and lipid efflux. We found a significant increase in expression of Abca1 and a significant decrease in expression of CD36 in cells harvested from the SN of LXR agonist-treated mice (Fig. 5C) $(n=8 /$ 

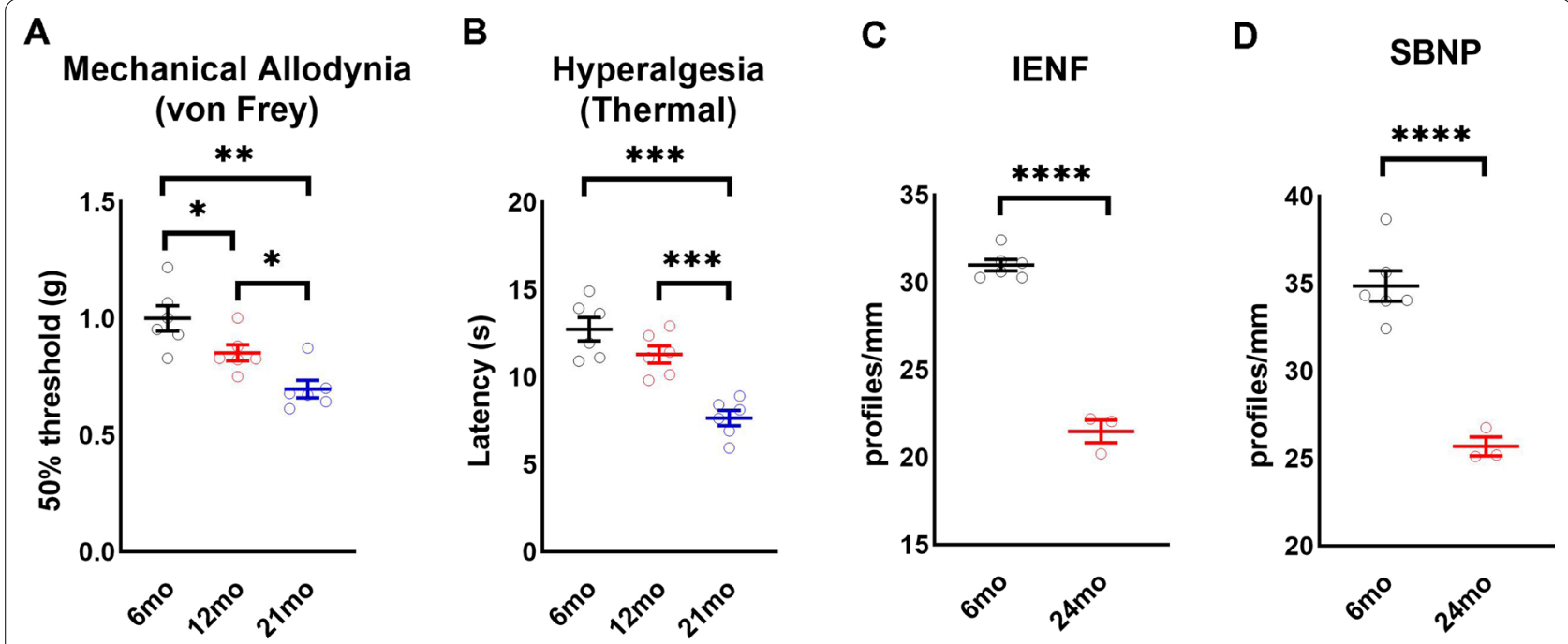

$\mathbf{E}$
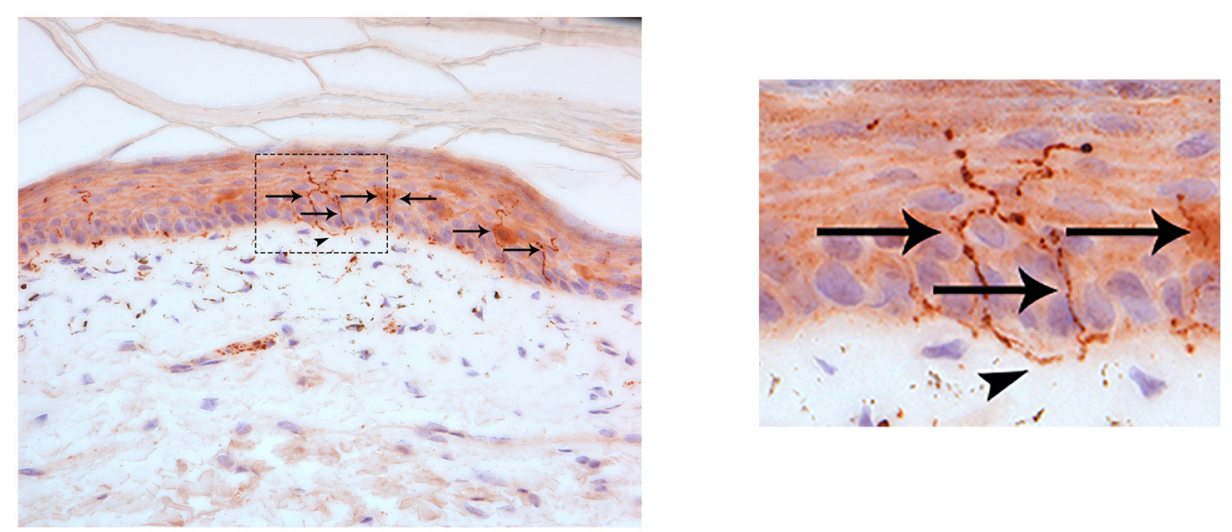

Epidermis

$6 \mathrm{mo}$
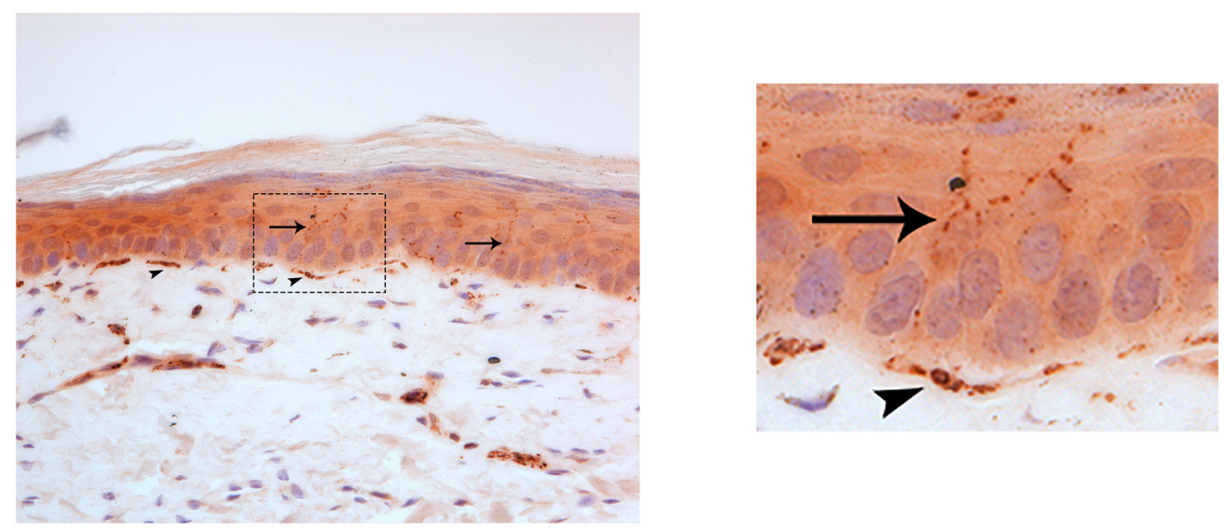

$24 \mathrm{mo}$

Fig. 2 Aging leads to loss of distal nerve and neuropathy. A Mechanical allodynia in 6, 12, and 21 month-old mice ( $n=6 / g r o u p)$. B Thermal hyperalgesia in 6,12 , and 21 month-old mice ( $n=6 /$ group). Distal nerve quantification in 6 and 24 month-old mice, IENF C and SBNP D $(n=3-5 /$ group). E Representative images of paw plantar skin of 6 and 24 month-old mice used for IENF quantification. PGP9.5 positive nerve fibers stain brown. Black arrows indicate intra-epidermal nerve fibers and arrowheads indicate dermal nerves. All images were obtained at $40 \times$ magnification. All data are Mean \pm SEM. ${ }^{*} p<0.05,{ }^{* *} p<0.005,{ }^{* * *} p<0.0005,{ }^{* * * *} p<0.00005$ 

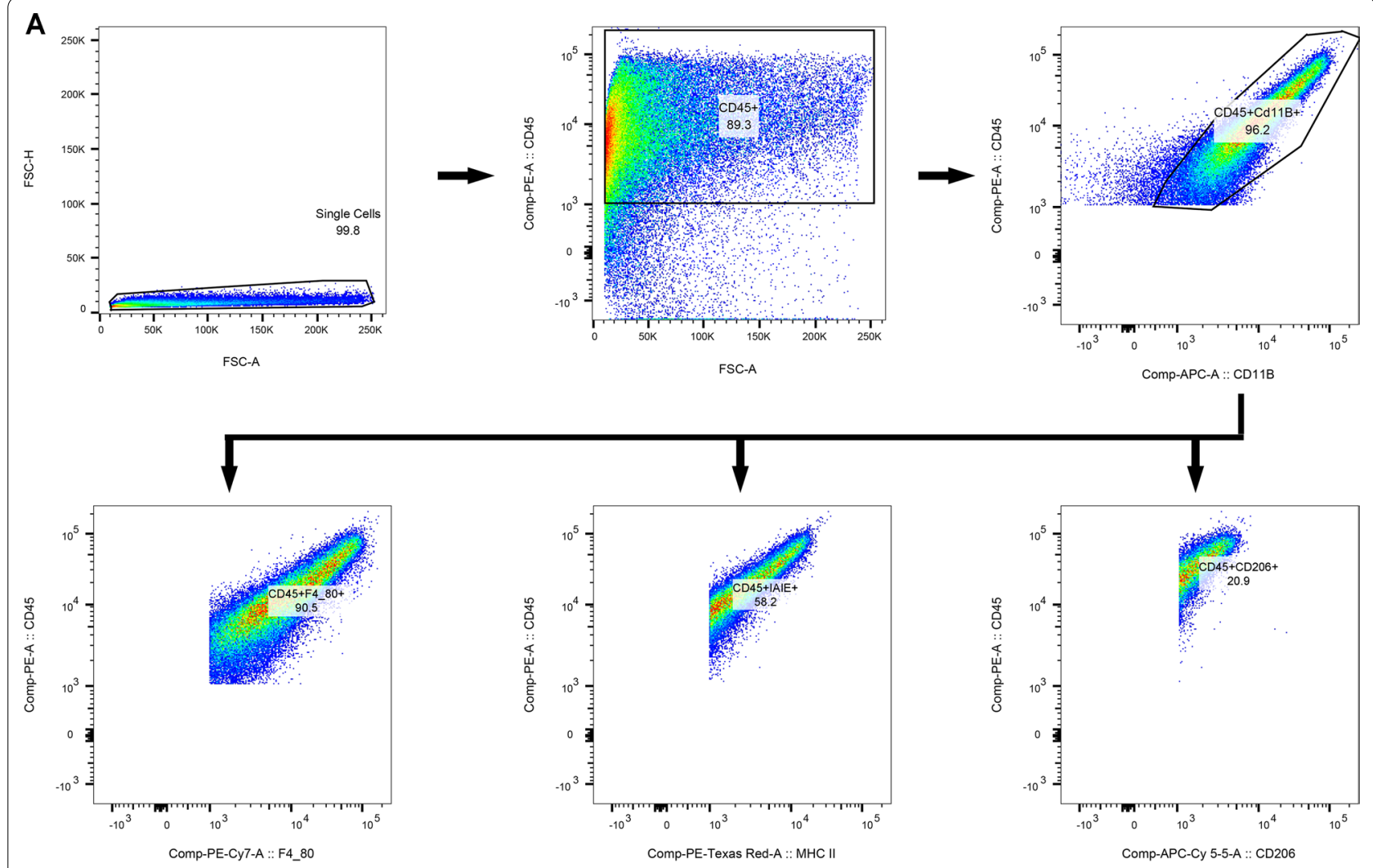

B
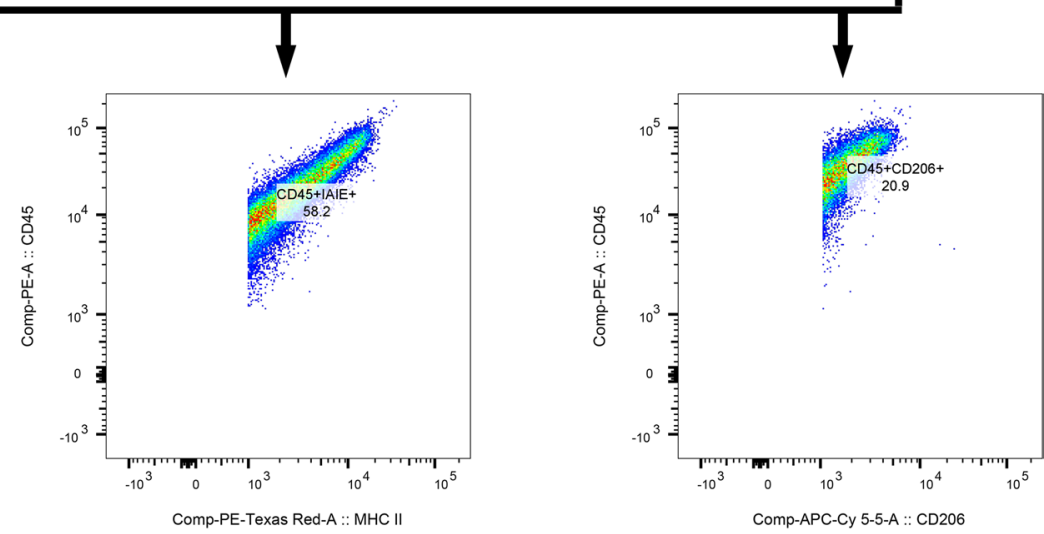

DRG

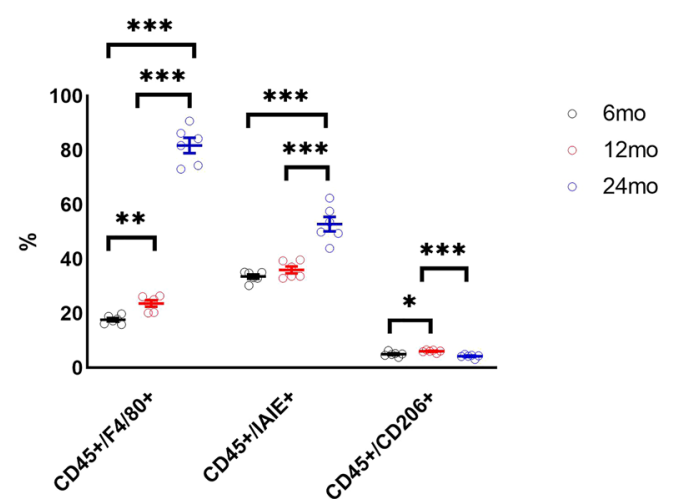

C

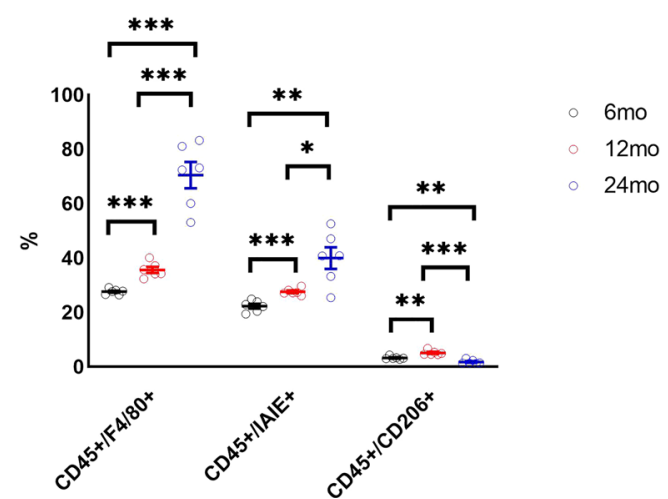

Fig. 3 Activated macrophage numbers and their phenotype change with age. A Gating strategy used for sorting and quantifying macrophage population. B Percentage macrophage population and phenotypes in the DRG of 6,12 , and 24 month-old mice $(n=6 /$ group). C Percentage macrophage population and phenotypes in the SN of 6, 12, and 24 month-old mice $\left(n=6 /\right.$ group). All data are Mean \pm SEM. ${ }^{*} p<0.05,{ }^{* *} p<0.005$, ***p $<0.0005$

group). We also found significantly decreased cholesterol content in sorted cells from mice treated with GW3965 compared to vehicle treated mice (Fig. 5D) ( $n=8$ /group). Differentiated macrophages derived from bone marrow of old mice were culture in presence of oxidized low-density lipoproteins (oxLDL) to obtaining many lipid-loaded cells $[50,51]$, and then treated with GW3965. Consistent with data on SN and literature [52, 53], we found a significantly lower percentage of cells labeled with oxLDL in GW3965 treated group (Fig. 5E, G) $(n=3$ experiments in triplicate). Within the cells that were positive for oxLDL, GW3965 treated cells had significantly lower content of oxLDL compared to vehicle treated cells (Fig. 5F, G) ( $n=50$ cells/group). 


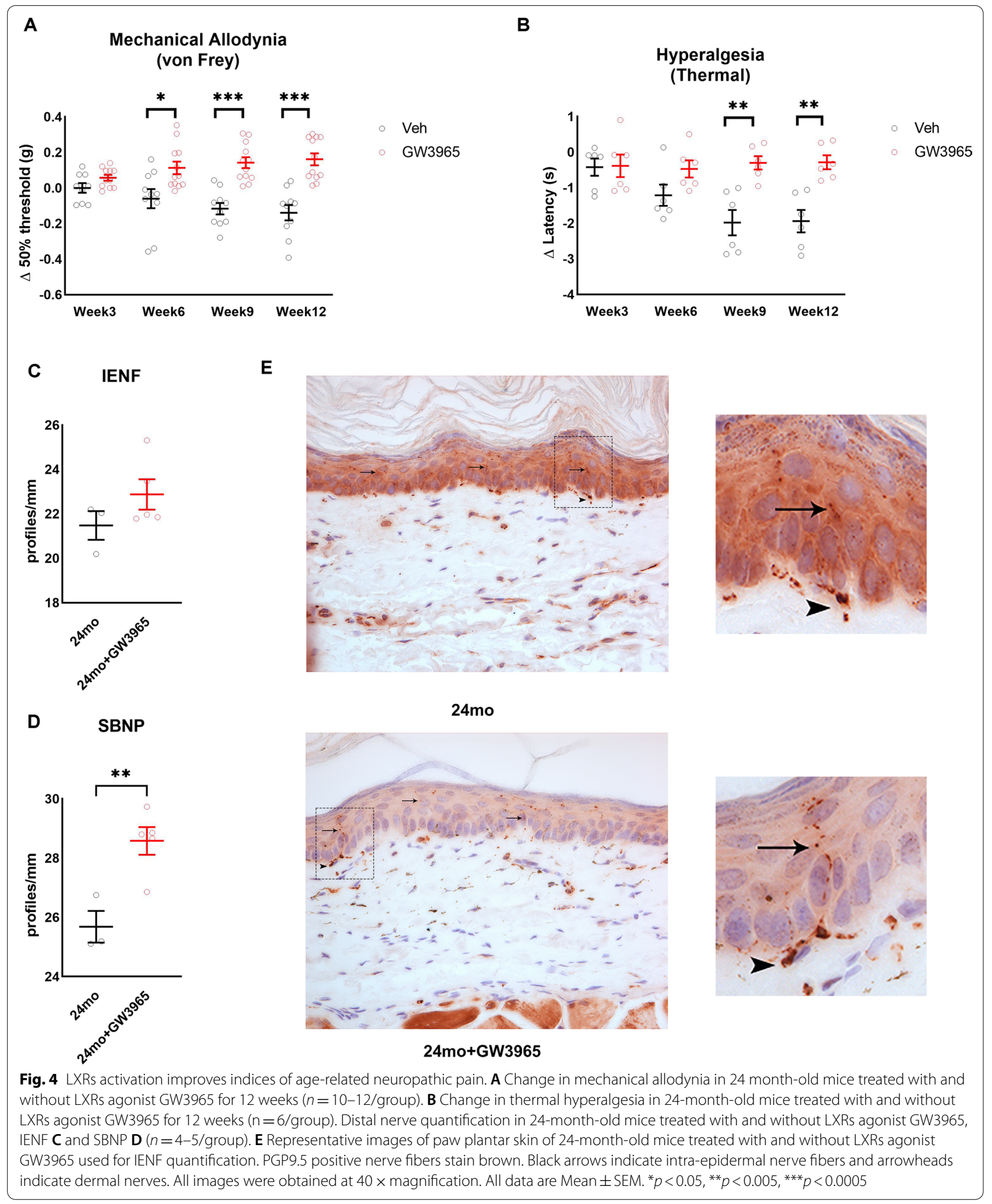


To test if LXRs activation and potentially lipid content affected macrophage metabolism, we measured oxygen consumption rate (OCR) in differentiated macrophages derived from bone marrow of old mice with or without concurrent GW3965 (Fig. 6A) ( $n=15$ wells/group). Compared to vehicle, LXRs agonist treatment significantly increased basal respiration (Fig. 6B) ( $n=15$ wells/ group) and basal glycolytic activity (basal ECAR, Fig. 6C) $(n=15$ wells/group). LXRs activation also significantly increased maximal respiration (Fig. 6D) ( $n=15$ wells/ group), proton leak (Fig. 6E) ( $n=15$ wells/group), and non-mitochondrial oxygen consumption (Fig. $6 \mathrm{~F})(n=15$ wells/group), without having a significant effect on spare respiratory capacity, coupling efficiency, or ATP-linked oxygen consumption (not shown). These data suggest that LXRs activation changes the metabolism of macrophages exhibiting energetic phenotype.

\section{Discussion}

Aging is a major risk factor for damage to the structure and function of the PNS [54]. We observed a significant decrease in the mechanical threshold and latency for thermal hyperalgesia of mice with age, suggesting an increased sensitivity to innocuous stimuli with age. Here, we confirm previous studies showing that aged mice (24 months) exhibit sensory dysfunction, loss of distal sensory fibers and elevated endoneurial macrophages $[6,55,56]$. Endoneurial macrophages, both resident and invading, are widely studied in the context of their capacity to phagocytose debris following physical nerve injury, a process that paves the way for nerve regeneration, while dysregulation of the immune system can prompt macrophages to inappropriately attack Schwann cells and myelin in autoimmune and inflammatory neuropathies. [21-24]. Inflammatory response develops rapidly after peripheral nerve injury, which contributes to both neuropathic pain and nerve regeneration [14]. Therefore, it is crucial to study immune cells in pathophysiology or after nerve injury to identify new innovative targets for treating neuropathic pain. Both circulating and resident macrophage populations may contribute to the pathogenesis of PNS injuries. Resident macrophages are the early responders upon peripheral nerve injury, digesting myelin as soon as 2 days after sciatic nerve crush [57]. Over time, the ratio of number of infiltrating macrophages outweighs resident macrophages following nerve injury, but little is known whether they have distinct functions in the PNS and in aging [58]. Resident macrophages in the PNS possess a microglia-like phenotype, which includes the removal of debris, inflammation, and remyelination during injury [59]. Intriguingly, a contribution of macrophages to the pathogenesis of age-related neuropathy has recently been suggested by a report that silencing of foamy macrophages in the PNS improved the nerve structure and function of aged mice [6]. Despite evidence for a role of macrophages loaded with lipid in the development of age-related neuropathy, the mechanism is not known. The presence of phagocyting macrophages, while necessary for a healthy nerve structure and function, may also induce nerve damage via dysfunction in lipid efflux and clearance by phagocytic immune cells.

We have previously reported that activation of LXR in the sensory neurons of the DRG is required for amelioration of obesity-induced allodynia, and that selective deletion of LXRs from sensory neurons enhances the neuropathic pain phenotype [10]. LXRs agonist, GW3965, has been shown to promote the recovery of damaged nerves in many acute models of nerve injury. Indeed, administration of GW3965 following sciatic nerve crush prevents the development of mechanical allodynia and is concomitant with an increase in M2-phenotype of resident macrophages, thus contributing to the resolution of inflammation and promotion of tissue repair [60]. In a mouse model of demyelination using lysolecithin injection, GW3965 promotes myelin debris clearance through the upregulation of LXRregulated cholesterol transport genes in macrophages, including ApoE, Abca1, and Abcg1 [61]. We found that the LXR selective agonist GW3965 either reversed or delayed the progression of multiple functional and structural indices of neuropathy observed in aged mice. Treating 24-month-old mice with GW3965 prevented first the development of mechanical hypersensitivity and then thermal hyperalgesia over time. This improvement in pain indices was also accompanied with an increase in SBNP density suggesting LXRs activation either attenuated distal degeneration or stimulated nerve regeneration. This is consistent with our prior studies that showed

(See figure on next page.)

Fig. 5 Activation of LXRs increases lipid efflux. A Percentage macrophage population and phenotypes in the DRG of 24-month-old mice treated with and without LXRs agonist GW3965 ( $n=6-9 /$ group). B Percentage macrophage population and phenotypes in the SN of $24-m o n t h-o l d ~ m i c e$ treated with and without LXRs agonist GW3965 ( $n=6-9 /$ group). C mRNA expression of LXRs target genes in the sorted CD45 + CD11B + cells from the SN of 24-month-old mice treated with and without LXRs agonist GW3965 ( $n=8 /$ group). D Cholesterol content in the sorted CD45 + CD11B + cells from the SN of 24-month-old mice treated with and without LXRs agonist GW3965 ( $n=8 / \mathrm{group})$. E Percentage oxLDL positive cells from macrophages treated with and without LXRs agonist GW3965 ( $n=3$ experiments in triplicate). $\mathbf{F}$ oxLDL relative intensity in oxLDL positive cells from macrophages treated with and without LXRs agonist GW3965 ( $n=50$ cells/group). G Representative images of oxLDL positive cells from macrophages treated with and without LXRs agonist GW3965. Arrows represent macrophages with oxLDL staining (oxLDL-red, nucleus-DAPI/blue) and arrowheads represent macrophages without oxLDL staining. All data are Mean \pm SEM. ${ }^{*} p<0.05,{ }^{* *} p<0.005,{ }^{* * *} p<0.0005$ 
A

DRG

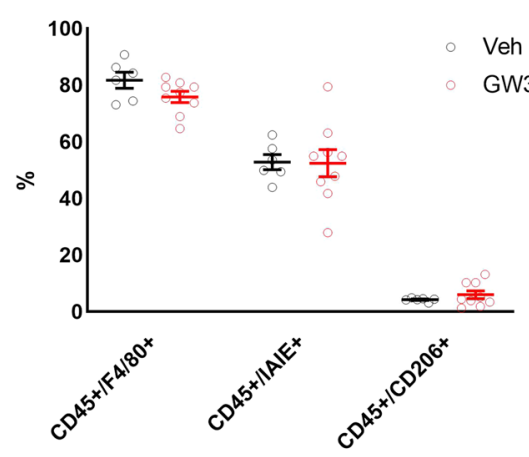

C

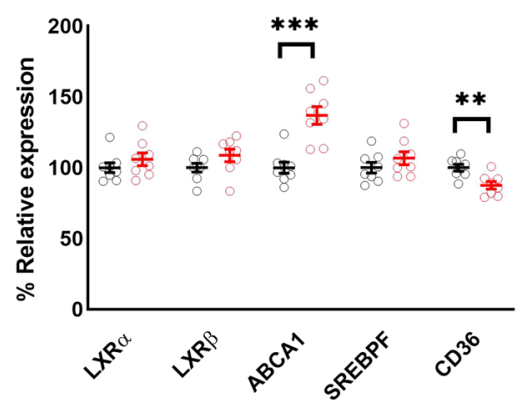

E

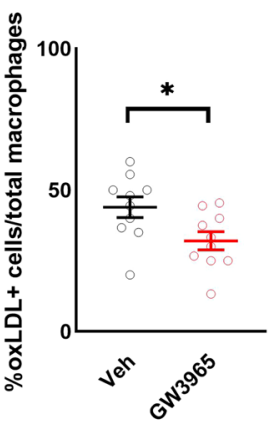

$\mathbf{F}$

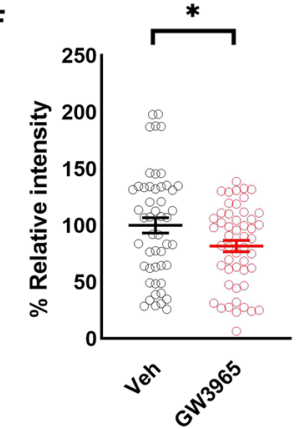

B

Veh

GW3965

GW3965

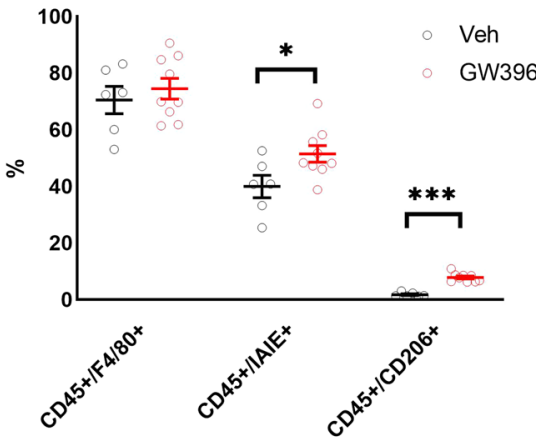

D
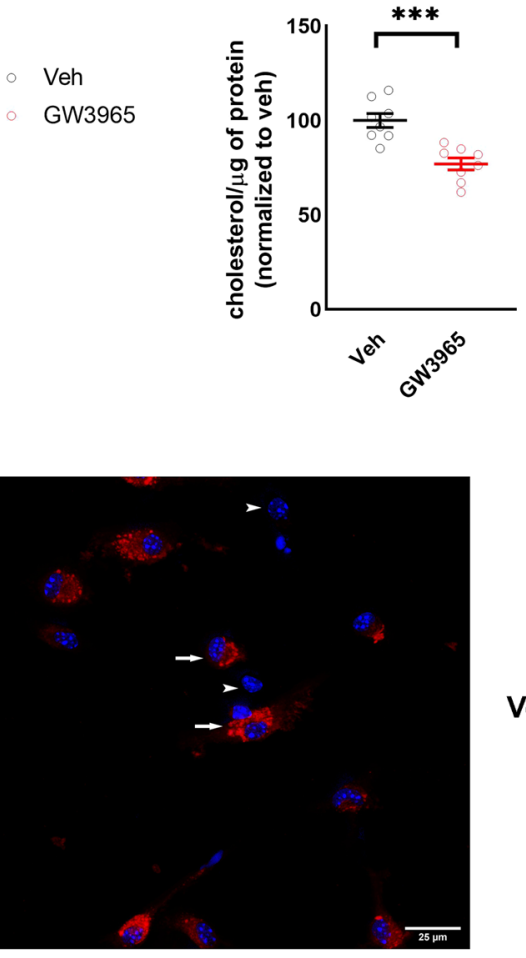

Veh

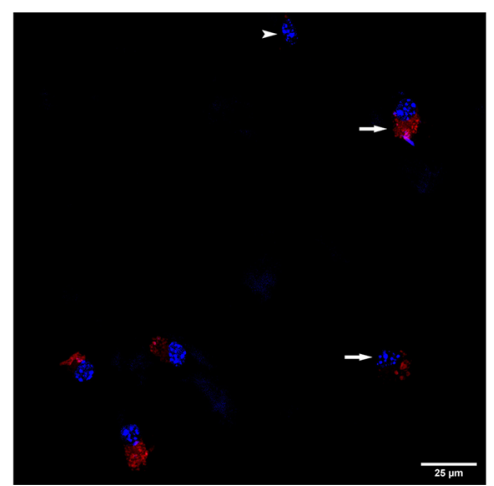

GW3965 


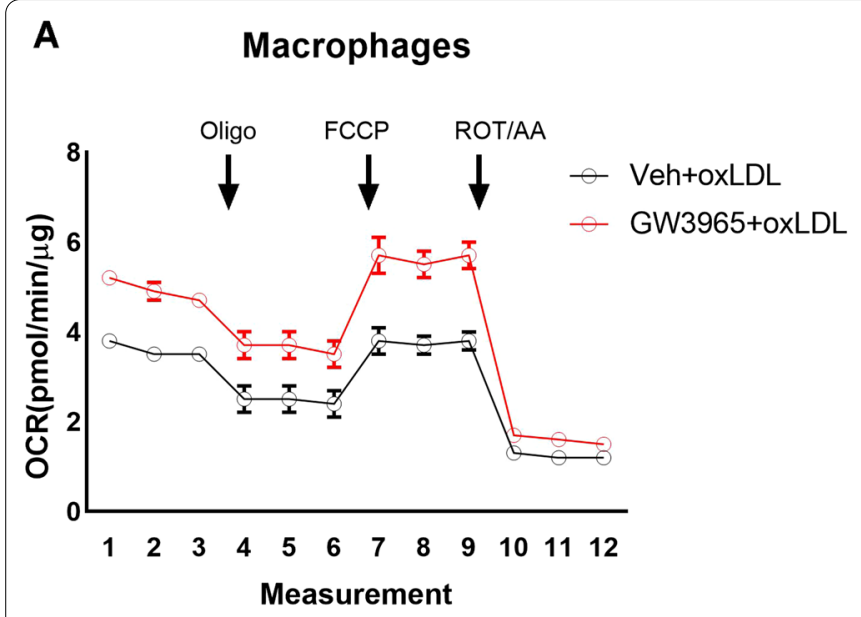

B
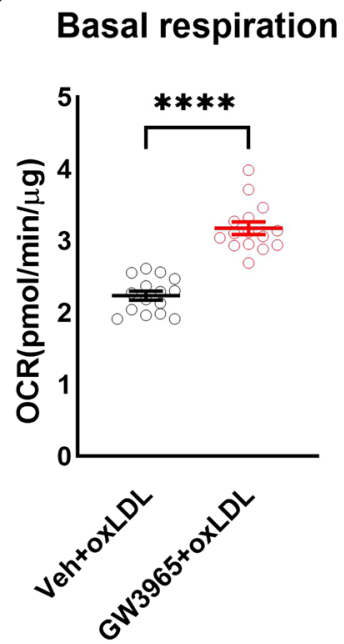

C

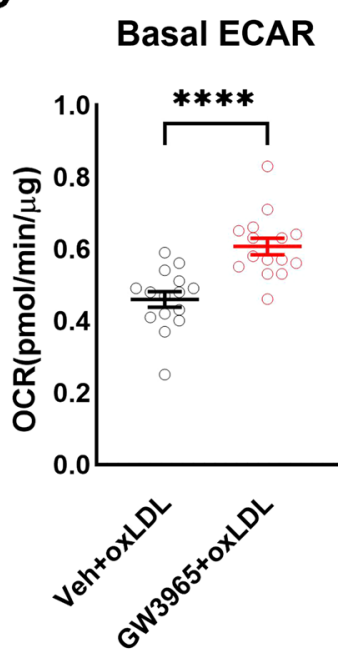

D

Maximal Respiration

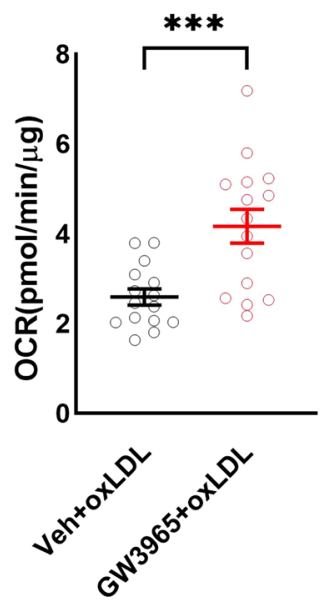

E

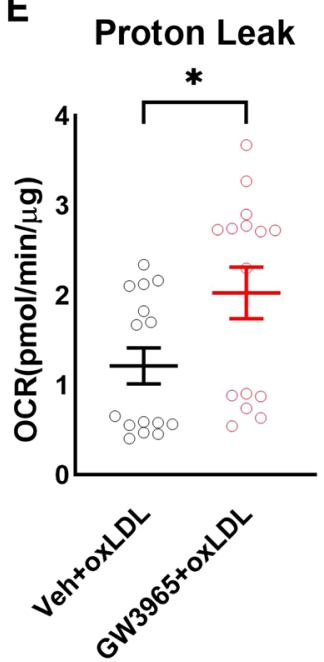

$\mathbf{F}$

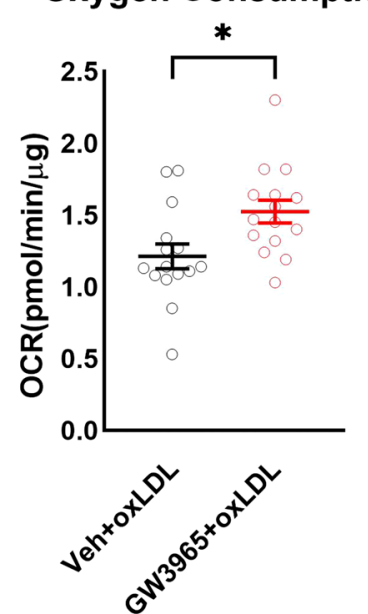

Fig. 6 Activation of $L X R s$ is associated with change in macrophage polarization. During oxygen consumption assay in the presence of ox $L D L$ and with and without LXRs agonist GW3965 (A), LXRs activation significantly increased basal respiration (B), basal ECAR (C), maximal respiration (D), proton leak (E), and non-mitochondrial oxygen consumption $\mathbf{F}$ ( $n=15$ wells/group). All data are Mean \pm SEM. ${ }^{*} p<0.05,{ }^{* * *} p<0.0005$, ${ }^{* * *} p<0.00005$

LXR agonist treatment prevents progression of obesityinduced allodynia by altering peripheral sensory neuron function and their interaction with associated cells [10, 62]. Peripheral macrophages have been implicated in the development of mechanical allodynia [63] and infiltration by immune cells happen differently in myelinated or non-myelinated fibers that may explain temporal differences in sensory behavior. In addition, a recent report showed that transcriptional changes in DRG caused by nerve injury correlated with temporal changes in nocifensive behavior-changes observed in nociceptor-related transcripts correlated with the early development of thermal allodynia, while changes observed in immunerelated genes correlated with the later development of tactile allodynia [63]. These findings may be pertinent to the differences we observed in normalization of mechanical and thermal sensitivities in aging. We also observed that LXR agonist increases the fiber density in the skin of aged mice. Loss of IENF is usually associated with neuropathic pain, many reports suggest various mechanisms but there is still a lack of consensus that explains why less fibers lead to pain [64, 65]. Many reports converge toward the conclusion that while some neurons are retracting, neurons become hyperexcitable 
for various reasons, leading to pain. Previous studies have shown IENF loss in patients with diabetes, but was also observed in patients with diabetes but without pain [65]. This loss of IENF does not explain pain. It is possible, however, that patients with pronounced loss would develop these pain symptoms later. Others have reported a specific relationship between loss of IENF and changes in thermal perception, but found that pain and aberrant thermal perception resolved before IENFs reinnervated the skin [66]. There are likely distinct mechanisms regulating the loss of IENF and progression of neuropathic pain and crosstalk between these pathways may occur in some cases. While more investigation would be necessary to establish causality, our findings suggest that activation of LXRs influence sensory perception and nerve degeneration/regeneration of the aged mice via modifying macrophages of the SN. Our exploratory study using two human sural nerves suggests an age-related difference in macrophage polarization and encourages future additional studies using larger numbers.

LXRs are oxidized cholesterol derivative ligand-activated transcription factors and consist of two isoforms LXR $\alpha$ and LXR $\beta[10,30,31,62]$. LXRs play an important role in cholesterol metabolism [32, 33]. Several studies have reported that activation of LXRs inhibit the development of atherosclerosis, a property attributed to LXRmediated ABCA1 expression and cholesterol efflux in macrophages [52, 53]. LXRs also play an important role in the regulation of cytokine production and the antiinflammatory response [32, 33]. In this study, we provide evidence supporting the potential role of LXR activation in the regulation of PNS macrophage cholesterol content. A number of anti-inflammatory mechanisms have been proposed to explain the actions of LXRs in other tissues including direct repression of pro-inflammatory gene promoters, cholesterol efflux, changes in plasma membrane signaling systems via modulation of membrane lipid composition, and increased synthesis of fatty acids with anti-inflammatory activity [32, 67, 68]. The engulfment of myelin and other cellular debris in injured nerve by macrophages is associated with acute changes in their cellular lipid levels [35], including intracellular-free cholesterol. Activation of LXRs during this process promotes the efflux of free cholesterol by activation of ABCA1 [52, 53].

Our data demonstrate that the amount of cholesterol within macrophages sorted from the SN of aged mice is decreased after activation of LXR. An emerging body of evidence indicates that cellular metabolism determines macrophage function as either pro- or anti-inflammatory [69]. However, the role of lipid content in PNS macrophage polarization is unknown. We failed to obtain enough macrophages from $\mathrm{SN}$ of mice so to assess macrophages' bioenergetic profiles, so we used aged bone-marrow-derived macrophages cultured in oxLDL to maximize the lipid-loading of the cells. After treatment with the LXRs activator GW3965, we find that these macrophages increase both OCR and ECAR. This metabolic flux results imply that both glycolysis (ECAR) and mitochondrial respiration (OCR) are upregulated in macrophages treated with GW3965, potentially mimicking the energetic M2 phenotype [69]. Altogether, our data indicate that activation of LXRs in the PNS could induce phenotypic alteration of immune cells-by restoring or activating the lipid efflux in peripheral macrophages-resulting in a sensory and neuropathy improvement in aged mice.

\section{Conclusions}

We demonstrated that neuropathic alterations in aging mice were accompanied by changes in macrophage profiles. Even though lacking power, we saw similar data in human sural nerve. LXR agonist, GW3965, can delay age-related alterations to mechanical hypersensitivity and hyperalgesia, and increase sensory nerve fibers of the skin potentially resulting from an LXR-dependent regulation of macrophage cholesterol/lipid metabolism. However, future studies are required to dig deeper into comprehensive molecular mechanisms linking PNS/ lipid/macrophage and to investigate whether LXRs activation attenuated distal degeneration or stimulated nerve regeneration in aging mice. Metabolic syndrome and neuropathy are closely associated and has been shown to be one of the driving factor for nerve injury in aged population by increasing fatty deposition in nerves, mitochondrial dysfunction, and oxidative stress [70]. Activation of these pathways also leads to metabolic inflammation [70]. Further studies in lipid metabolism of immune cells/macrophages of aging mice may advance our understanding of the pathophysiology of age-related neuropathic pain and help us in increasing the quality of life in the elderly.

\section{Abbreviations}

ABCA1: ATP binding cassette transporter A1; ATP: Adenosine triphosphate; CD11B: Cluster of differentiation 11b, leukocyte marker; CD206: Cluster of differentiation 206, M2 macrophage marker; CD36: Cluster of differentiation 36, scavenger receptor; CD45: Cluster of differentiation 45, lymphocyte common antigen; DAPI: Diamidino-2-phenylindole; Dil-oxLDL: Dil dye oxidized lowdensity lipoproteins; DRG: Dorsal root ganglia; ECAR: Extracellular acidification rate; ETC: Electron transport chain; F4/80: Macrophage marker; FBS: Fetal bovine serum; FCCP: Carbonyl cyanide-4-(trifluoromethoxy)phenylhydrazone; I-A/I-E: MHC class II marker; IENF: Intraepidermal nerve fibers; LXR: Liver $X$ receptor; OCR: Oxygen consumption rate; OxLDL: Oxidized low-density lipoproteins; PBS: Phosphate buffered saline; PNS: Peripheral nervous system; RPMI-1640: Roswell park memorial institute medium-1640; SBNP: Sub-basal nerve plexus; SN: Sciatic nerve; SREBPF: Sterol regulatory element-binding transcription factor 1. 


\section{Supplementary Information}

The online version contains supplementary material available at https://doi. org/10.1186/s12974-022-02423-z.

Additional file 1: Fig. S1. A Percentage of $\mathrm{M} 1(\mathrm{CD} 45+/ \mathrm{HLA}-\mathrm{DR}+)$ and M2 (CD45 +/CD206 +) macrophages in human sural nerve biopsies from 37 and 84yrs old female patients. B mRNA expression of $L$ XRs target genes in the sorted CD45 +CD11B + cells from the SN of 6-month-old and 24-month-old mice ( $n=8 /$ group). C Cholesterol content in the sorted CD45 + CD11B + cells from the SN of 6, 12, and 24 month-old mice ( $n=8$ /group). Cholesterol $\mathbf{D}$ and triglycerides $\mathbf{E}$ levels of 24-month-old mice treated with and without LXRs agonist GW3965 for 12 weeks $(n=6$ / group). All data are Mean \pm SEM. ${ }^{*} p<0.05,{ }^{* *} p<0.005,{ }^{* * *} p<0.0005$, ${ }^{* * *} p<0.00005$

\section{Acknowledgements}

We thank Loyola University Chicago animal facility for housing our mice.

\section{Authors' contributions}

CKG and VMA were involved in the conception and design of the experiments. $C K G, N E, A V G, G A, N A C$, and VMA were involved in data collection, assembly, analysis and interpretation of data. CKG and VMA drafted the manuscript. $\mathrm{CKG}, \mathrm{NE}, \mathrm{AVG}, \mathrm{GA}, \mathrm{NAC}$, and VMA revised the manuscript. All authors read" and approved the final manuscript.

\section{Funding}

This work was supported by National Institute of Diabetes and Digestive and Kidney Diseases (NIH) R01 DK117404 to VMA.

\section{Availability of data and materials}

All data generated or analyzed during this study are included in this published article [and its Additional file 1: Fig. S1].

\section{Declarations}

\section{Ethics approval and consent to participate}

Informed consent was obtained from all human subjects prior to sural nerve sample collection in strict accordance with the rules and guidelines stipulated by the Loyola University Chicago Internal Review Board (IRB). All experimental protocols were approved by the Loyola University Chicago IRB (protocol \# 210567020519)

\section{Consent for publication}

Not applicable.

\section{Competing interests}

The authors declare that they have no competing interests.

\section{Author details}

${ }^{1}$ Cell and Molecular Physiology, Stritch School of Medicine, Loyola University Chicago, Maywood, IL 60153, USA. ${ }^{2}$ Department of Neurological Surgery, Loyola University Medical Center, Maywood, IL 60153, USA. ${ }^{3}$ Departement of Internal Medicine, Division of Cardiology, Loyola University Medical Center Maywood, IL 60153, USA. ${ }^{4}$ Department of Pathology, University of California San Diego, La Jolla, CA 92093, USA.

Received: 12 October 2021 Accepted: 22 February 2022 Published online: 26 February 2022

\section{References}

1. Goss JR, Stolz DB, Robinson AR, Zhang M, Arbujas N, Robbins PD, et al. Premature aging-related peripheral neuropathy in a mouse model of progeria. Mech Ageing Dev. 2011;132(8-9):437-42.

2. Giovannini S, Coraci D, Brau F, Galluzzo V, Loreti C, Caliandro P, et al. Neuropathic pain in the elderly. Diagnostics (Basel, Switzerland). 2021:11(4):613.
3. Mold JW, Vesely SK, Keyl BA, Schenk JB, Roberts M. The prevalence, predictors, and consequences of peripheral sensory neuropathy in older patients. J Am Board Fam Pract. 2004;17(5):309-18.

4. Richardson JK. The clinical identification of peripheral neuropathy among older persons. Arch Phys Med Rehabil. 2002;83(11):1553-8.

5. Brisset M, Nicolas G. Peripheral neuropathies and aging. Geriatr Psychol Neuropsychiatr Vieil. 2018;16(4):409-13.

6. Yuan X, Klein D, Kerscher S, West BL, Weis J, Katona I, et al. Macrophage depletion ameliorates peripheral neuropathy in aging mice. J Neurosci. 2018;38(19):4610-20.

7. Ugrenović S, Jovanović I, Vasović L, Kundalić B, Čukuranović R, Stefanović $V$. Morphometric analysis of the diameter and g-ratio of the myelinated nerve fibers of the human sciatic nerve during the aging process. Anat Sci Int. 2016;91(3):238-45.

8. Hanewinckel R, van Oijen M, Ikram MA, van Doorn PA. The epidemiology and risk factors of chronic polyneuropathy. Eur J Epidemiol. 2016;31(1):5-20.

9. Chia L, Fernandez A, Lacroix C, Adams D, Planté V, Said G. Contribution of nerve biopsy findings to the diagnosis of disabling neuropathy in the elderly. A retrospective review of 100 consecutive patients. Brain. 1996;119(Pt 4):1091-8.

10. Gavini CK, Bookout AL, Bonomo R, Gautron L, Lee S, Mansuy-Aubert V. Liver $X$ receptors protect dorsal root ganglia from obesity-induced endoplasmic reticulum stress and mechanical allodynia. Cell Rep. 2018:25(2):271-7.e4

11. Vincent AM, Hayes JM, McLean LL, Vivekanandan-Giri A, Pennathur S, Feldman EL. Dyslipidemia-induced neuropathy in mice: the role of oxLDL/LOX-1. Diabetes. 2009;58(10):2376-85.

12. Vincent AM, Calabek B, Roberts L, Feldman EL. Biology of diabetic neuropathy. Handb Clin Neurol. 2013;115:591-606.

13. Ristoiu V. Contribution of macrophages to peripheral neuropathic pain pathogenesis. Life Sci. 2013;93(23):870-81.

14. DeFrancesco-Lisowitz A, Lindborg JA, Niemi JP, Zigmond RE. The neuroimmunology of degeneration and regeneration in the peripheral nervous system. Neuroscience. 2015:302:174-203.

15. Hidmark AS, Nawroth PP, Fleming T. Analysis of immune cells in single sciatic nerves and dorsal root ganglion from a single mouse using flow cytometry. JoVE. 2017;130:56538.

16. Mokarram N, Merchant A, Mukhatyar V, Patel G, Bellamkonda RV. Effect of modulating macrophage phenotype on peripheral nerve repair. Biomaterials. 2012;33(34):8793-801.

17. Martini $\mathrm{R}$, Willison $\mathrm{H}$. Neuroinflammation in the peripheral nerve: cause, modulator, or bystander in peripheral neuropathies? Glia. 2016;64(4):475-86

18. Hu P, McLachlan EM. Distinct functional types of macrophage in dorsal root ganglia and spinal nerves proximal to sciatic and spinal nerve transections in the rat. Exp Neurol. 2003;184(2):590-605.

19. Simeoli R, Montague K, Jones HR, Castaldi L, Chambers D, Kelleher JH, et al. Exosomal cargo including microRNA regulates sensory neuron to macrophage communication after nerve trauma. Nat Commun. 2017:8(1):1778

20. Yu X, Liu H, Hamel KA, Morvan MG, Yu S, Leff J, et al. Dorsal root ganglion macrophages contribute to both the initiation and persistence of neuropathic pain. Nat Commun. 2020;11(1):264.

21. Zigmond RE, Echevarria FD. Macrophage biology in the peripheral nervous system after injury. Prog Neurobiol. 2019;173:102-21.

22. Gaudet AD, Popovich PG, Ramer MS. Wallerian degeneration: gaining perspective on inflammatory events after peripheral nerve injury. J Neuroinflamm. 2011;8:110.

23. Cattin A-L, Burden JJ, Van Emmenis L, Mackenzie FE, Hoving JJA, Garcia Calavia N, et al. Macrophage-induced blood vessels guide schwann cellmediated regeneration of peripheral nerves. Cell. 2015;162(5):1127-39.

24. Dun X-P, Carr L, Woodley PK, Barry RW, Drake LK, Mindos T, et al. Macrophage-derived slit3 controls cell migration and axon pathfinding in the peripheral nerve bridge. Cell Rep. 2019;26(6):1458-72.e4.

25. Koike H, Katsuno M. The role of macrophages in Guillain-Barré syndrome and chronic inflammatory demyelinating polyneuropathy. Neurol Clin Neurosci. 2021;9(3):203-10.

26. Martini R, Fischer S, López-Vales R, David S. Interactions between Schwann cells and macrophages in injury and inherited demyelinating disease. Glia. 2008:56(14):1566-77. 
27. Jin HY, Park TS. Role of inflammatory biomarkers in diabetic peripheral neuropathy. J Diabetes Investig. 2018;9(5):1016-8.

28. Pop-Busui R, Ang L, Holmes C, Gallagher K, Feldman EL. Inflammation as a therapeutic target for diabetic neuropathies. Curr Diab Rep. 2016;16(3):29.

29. Gibson MS, Domingues N, Vieira OV. Lipid and non-lipid factors affecting macrophage dysfunction and inflammation in atherosclerosis. Front Physiol. 2018;9:654.

30. Chawla A, Repa JJ, Evans RM, Mangelsdorf DJ. Nuclear receptors and lipid physiology: opening the X-files. Science. 2001;294(5548):1866-70.

31. Repa JJ, Mangelsdorf DJ. Nuclear receptor regulation of cholesterol and bile acid metabolism. Curr Opin Biotechnol. 1999;10(6):557-63.

32. Joseph SB, Castrillo A, Laffitte BA, Mangelsdorf DJ, Tontonoz P. Reciprocal regulation of inflammation and lipid metabolism by liver $X$ receptors. Nat Med. 2003;9(2):213-9.

33. Pascual-García M, Valledor AF. Biological roles of liver $\mathrm{X}$ receptors in immune cells. Arch Immunol Ther Exp. 2012;60(4):235-49.

34. Cermenati G, Giatti S, Cavaletti G, Bianchi R, Maschi O, Pesaresi M, et al. Activation of the liver $X$ receptor increases neuroactive steroid levels and protects from diabetes-induced peripheral neuropathy. J Neurosci. 2010:30(36):11896.

35. Noelia AG, Bensinger SJ, Hong C, Beceiro S, Bradley MN, Zelcer N, et al. Apoptotic cells promote their own clearance and immune tolerance through activation of the nuclear receptor LXR. Immunity. 2009;31(2):245-58.

36. Ma L, Dong F, Zaid M, Kumar A, Zha X. ABCA1 protein enhances Toll-like receptor 4 (TLR4)-stimulated interleukin-10 (IL-10) secretion through protein kinase A (PKA) activation. J Biol Chem. 2012;287(48):40502-12.

37. Kim SY, Lim EJ, Yoon YS, Ahn YH, Park EM, Kim HS, et al. Liver X receptor and STAT1 cooperate downstream of Gas6/Mer to induce anti-inflammatory arginase 2 expression in macrophages. Sci Rep. 2016;6:29673.

38. Pourcet B, Feig JE, Vengrenyuk Y, Hobbs AJ, Kepka-Lenhart D, Garabedian MJ, et al. LXRa regulates macrophage arginase 1 through PU.1 and interferon regulatory factor 8. Circ Res. 2011;109(5):492-501.

39. du Percie Sert N, Hurst V, Ahluwalia A, Alam S, Avey MT, Baker M, et al. The ARRIVE guidelines 2.0: Updated guidelines for reporting animal research. PLoS Biol. 2020;18(7):e3000410.

40. Jolivalt CG, Frizzi KE, Guernsey L, Marquez A, Ochoa J, Rodriguez M, et al. Peripheral neuropathy in mouse models of diabetes. Curr Protoc Mouse Biol. 2016;6(3):223-55

41. Bala U, Tan KL, Ling KH, Cheah PS. Harvesting the maximum length of sciatic nerve from adult mice: a step-by-step approach. BMC Res Notes. 2014:7:714.

42. Bonomo RR, Cook TM, Gavini CK, White CR, Jones JR, Bovo E, et al. Fecal transplantation and butyrate improve neuropathic pain, modify immune cell profile, and gene expression in the PNS of obese mice. Proc Natl Acad Sci U S A. 2020;117(42):26482-93.

43. Shen S, Lim G, You Z, Ding W, Huang P, Ran C, et al. Gut microbiota is critical for the induction of chemotherapy-induced pain. Nat Neurosci. 2017:20(9):1213-6.

44. Hidmark AS, Nawroth PP, Fleming T. Analysis of immune cells in single sciatic nerves and dorsal root ganglion from a single mouse using flow cytometry. J Vis Exp. 2017. https://doi.org/10.3791/56538.

45. Weischenfeldt J, Porse B. Bone marrow-derived macrophages (BMM): isolation and applications. CSH Protoc. 2008. https://doi.org/10.1101/pdb. prot5080.

46. Gavini CK, White CR, Mansuy-Aubert V, Aubert G. Loss of C2-domain protein (C2CD5) alters hypothalamic mitochondrial trafficking, structure, and function. Neuroendocrinology. 2021. https://doi.org/10.1159/00051 7273.

47. Van den Bossche J, Baardman J, de Winther MP. Metabolic characterization of polarized $\mathrm{m} 1$ and $\mathrm{m} 2$ bone marrow-derived macrophages using real-time extracellular flux analysis. JoVE. 2015;105:e53424.

48. Baardman J, Verberk SGS, Prange KHM, van Weeghel M, van der Velden S, Ryan DG, et al. A defective pentose phosphate pathway reduces inflammatory macrophage responses during hypercholesterolemia. Cell Rep. 2018:25(8):2044-52.e5.

49. Klein D, Martini R. Myelin and macrophages in the PNS: an intimate relationship in trauma and disease. Brain Res. 2016:1641(Pt A):130-8.

50. Rios FJO, Ferracini M, Pecenin M, Koga MM, Wang Y, Ketelhuth DFJ, et al. Uptake of oxLDL and IL-10 production by macrophages requires pafr and cd36 recruitment into the same lipid rafts. PLoS ONE. 2013:8(10):e76893.
51. Xu S, Huang Y, Xie Y, Lan T, Le K, Chen J, et al. Evaluation of foam cell formation in cultured macrophages: an improved method with Oil Red O staining and Dil-oxLDL uptake. Cytotechnology. 2010;62(5):473-81.

52. Tangirala RK, Bischoff ED, Joseph SB, Wagner BL, Walczak R, Laffitte BA, et al. Identification of macrophage liver $X$ receptors as inhibitors of atherosclerosis. Proc Natl Acad Sci U S A. 2002;99(18):11896-901.

53. Parikh N, Frishman WH. Liver $\times$ receptors: a potential therapeutic target for modulating the atherosclerotic process. Cardiol Rev. 2010;18(6):269-74.

54. Barrell K, Smith AG. Peripheral neuropathy. Med Clin North Am. 2019;103(2):383-97.

55. Verdú E, Butí M, Navarro X. Functional changes of the peripheral nervous system with aging in the mouse. Neurobiol Aging. 1996;17(1):73-7.

56. Verdú E, Ceballos D, Vilches JJ, Navarro X. Influence of aging on peripheral nerve function and regeneration. J Peripher Nerv Syst. 2000;5(4):191-208.

57. Mueller M, Wacker K, Ringelstein EB, Hickey WF, Imai Y, Kiefer R. Rapid response of identified resident endoneurial macrophages to nerve injury. Am J Pathol. 2001:159(6):2187-97.

58. Mueller M, Leonhard C, Wacker K, Ringelstein EB, Okabe M, Hickey WF, et al. Macrophage response to peripheral nerve injury: the quantitative contribution of resident and hematogenous macrophages. Lab Invest. 2003;83(2):175-85.

59. Wang PL, Yim AKY, Kim K-W, Avey D, Czepielewski RS, Colonna M, et al. Peripheral nerve resident macrophages share tissue-specific programming and features of activated microglia. Nat Commun. 2020. https://doi. org/10.1038/s41467-020-16355-w.

60. Mao Z, Huang R, Xu J, Guo R, Wei X. Liver X receptor a in sciatic nerve exerts an alleviating effect on neuropathic pain behaviors induced by crush injury. Neurochem Res. 2021:46(2):358-66.

61. Cantuti-Castelvetri L, Fitzner D, Bosch-Queralt M, Weil MT, Su M, Sen P, et al. Defective cholesterol clearance limits remyelination in the aged central nervous system. Science. 2018;359(6376):684-8.

62. Gavini CK, Bonomo R, Mansuy-Aubert V. Neuronal LXR regulates neuregulin 1 expression and sciatic nerve-associated cell signaling in western diet-fed rodents. Sci Rep. 2020;10(1):6396.

63. Cobos EJ, Nickerson CA, Gao F, Chandran V, Bravo-Caparrós I, GonzálezCano R, et al. Mechanistic differences in neuropathic pain modalities revealed by correlating behavior with global expression profiling. Cell Rep. 2018;22(5):1301-12.

64. Boyette-Davis J, Xin W, Zhang H, Dougherty PM. Intraepidermal nerve fiber loss corresponds to the development of taxol-induced hyperalgesia and can be prevented by treatment with minocycline. Pain. 2011;152(2):308-13

65. Sorensen L, Molyneaux L, Yue DK. The relationship among pain, sensory loss, and small nerve fibers in diabetes. Diabetes Care. 2006;29(4):883-7.

66. Petersen KL, Rice FL, Farhadi M, Reda H, Rowbotham MC. Natural history of cutaneous innervation following herpes zoster. Pain. 2010;150(1):75-82.

67. Hong C, Tontonoz P. Coordination of inflammation and metabolism by PPAR and LXR nuclear receptors. Curr Opin Genet Dev. 2008;18(5):461-7.

68. Rong X, Albert CJ, Hong C, Duerr MA, Chamberlain BT, Tarling EJ, et al. LXRs regulate ER stress and inflammation through dynamic modulation of membrane phospholipid composition. Cell Metab. 2013;18(5):685-97.

69. Rodríguez-Prados JC, Través PG, Cuenca J, Rico D, Aragonés J, Martín-Sanz $P$, et al. Substrate fate in activated macrophages: a comparison between innate, classic, and alternative activation. J Immunol. 2010;185(1):605-14.

70. Callaghan B, Feldman E. The metabolic syndrome and neuropathy: therapeutic challenges and opportunities. Ann Neurol. 2013;74(3):397-403.

\section{Publisher's Note}

Springer Nature remains neutral with regard to jurisdictional claims in published maps and institutional affiliations. 